\title{
A Review on the Novel Coronavirus and Its Effects on Children
}

\author{
Gholamreza Bahoush $^{1 *}$, Elham Zarei ${ }^{2}$ \\ ${ }^{1}$ Department of Pediatrics, Ali Asghar Children's Hospital, Faculty of Medicine, Iran University of Medical sciences, Tehran, Iran; \\ ${ }^{2}$ Department of Radiology, Ali Asghar Children's Hospital, Faculty of Medicine, Iran University of Medical Sciences, Tehran, Iran
}

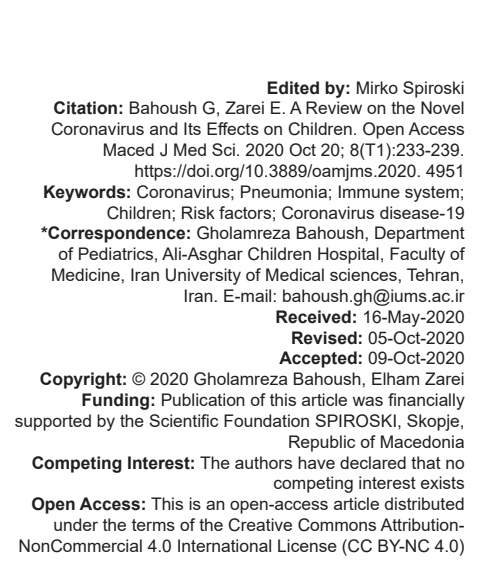

\section{Abstract}

BACKGROUND: The outbreak of the new coronavirus was first reported in China and then spread to other parts of the world. The number of people infected with the virus is significantly increasing, making the disease an international concern.

AIM: The present study aimed to investigate the coronavirus and its effects on children.

MATERIALS AND METHODS: In the present study, search engines, and scientific databases of Google Scholar Science Direct, PubMed, Medline, and Cochrane were searched to examine the effect of coronavirus on children. To collect information, keywords were also searched in the databases.

RESULTS: In spite of contradictory results, among the children, those under 5 years old are the high-risk group. CONCLUSION: Some researchers believe that the virus shows fewer symptoms in children. However, the immune system of infants under six months develops pneumonia in rare cases.

\section{Introduction}

Coronavirus (CoV) is a severe infectious agent in human and animal, which causes systemic disorder in respiratory and gastrointestinal tracts. CoV can infect certain species of animals, including mammals, bird, and reptiles [1]. On January 3, 2020, a new member of the CoV enveloped RNA was identified in bronchoalveolar lavage fluid samples of a patient in Wuhan and subsequently confirmed as the cause of the disease by the Centers for Disease Control and Prevention (CDC, China) [2]. The pathogenicity of this virus is that after the virus enters the body, it first binds to specific receptors on the cells with proper binding feature. Then, it enters the cell and uses its transcription machinery, multiplying it in large numbers and causing cellular damage [3].

Most of the patients are adults, with a small number of children. Out of 44,672 laboratory-confirmed cases of COVID-19 in China, only $2.1 \%$ are under 19 years old.

Studies have shown that COVID-19 has the highest mortality in the elderly. It also causes mild-tosevere respiratory problems in children, with mortality and morbidity lower than other age groups. Most children patients show mild symptoms, with no fever or signs of pneumonia [4], [5], [6], [7].
Given that one of the concerns of the health sector regarding the dangerous consequences of $\mathrm{CoV}$ is the dangers of this disease in a vulnerable community of children. There are many questions about the effect of the virus and ways to prevent children from getting the disease. An important issue is recognizing the virus and providing a reliable treatment strategy such as vaccination. Therefore, in the present study, an attempt is made to examine its effect on children and the proposed treatment options by examining the published articles on COVID-19 and the development of new CoV in children.

\section{Materials and Methods}

\section{Search strategy}

This evaluation was conducted in January and February 2020. Search engines and scientific databases of Google Scholar, Science Direct, PubMed, Medline, and Cochrane were used for obtaining papers on CoV and its effect on children. The keywords were also searched in the databases to collect information on the CoV, including corona, CoV and children, CoV pathogenesis, the virus structure, and COVID-19. 
Priority was given to articles from the past year. A reference list of relevant articles was searched to identify additional articles. In addition, search engines such as Google and Google Scholar were used to identify all potential eligible publications. The operators were used to find related articles. The study was conducted from July 5, 2020, to September 5, 2020.

\section{Inclusion and exclusion criteria}

Inclusion criteria included articles published after December 1997 to the end of January 2020, qualitative, descriptive, analytical study and articles published in English and Persian. Editorial letters, case studies, and clinical studies were excluded. Furthermore, articles with inadequate reports and a study whose full text was not available were excluded from the study.

\section{Screening and data mining}

A trained author performed search strategies. In the first stage, the titles and abstracts were reviewed for the selection of articles, in the next stage, an author independently reviewed the full text of the articles. Differences in findings were resolved through the criterion method of general conclusion of articles and in this study, were organized. Qualitative evaluation of articles was done by preparing a list of titles and summaries of studies in databases and selecting them based on the purpose of the study and content.

\section{CoVs}

CoVs are a large family of viruses that cause a flu-like illness in birds and mammals, accounting for $15-30 \%$ of common colds. They are spherical or polymorphic viruses containing a positive-sense single-stranded RNA with protein capsid nucleoprotein. There are several CoVs common between human and animal that usually cause mild-to-moderate infections in upper respiratory tract, such as the common cold. The virus rarely evolves and transmits from other animals to human. COVID-19 is a mutant of the CoVs family [2], [8].

The recombination rate of the virus is high because of the RNA-dependent RNA polymerase transcription (RdRPs) and constant transcription errors. However, despite the high mutation, CoVs are a zoonotic pathogens that vary between human and animal with a wide range of clinical manifestation from asymptomatic to requiring hospitalization due to infection in the respiratory, gastrointestinal, liver, and nervous systems [9], [10]. CoV is structurally related to middle East respiratory syndrome and severe acute respiratory syndrome (SARS).

\section{CoV, SARS, and MERS}

6LU7 is the COVID-19 main protease (Mpro), which been structured and repositioned in PDB and can be accessed by the public, as of early February 2020. The Mpro of 2019-nCov shares 96\% similarity with the Mpro of the SARS-CoV [11]. The Mpro in CoV is essential for the proteolytic maturation of the virus and has been examined as a potential target protein to prevent the spread of infection by inhibiting the cleavage of the viral polyprotein [12]. The discovery of the structure of the Mpro proteinase in COVID-19 provides an excellent opportunity to identify potential drug candidates for treatment.

Proteins represent potential targets for the inhibition of CoV replication, and the protein sequences of the SARS-CoV Mpro and 2019-nCoV Mpro are $96 \%$ identical, and the active sites in both proteins remain free from mutation. Thr24, Thr26, and Asn119 amino acids are predicted to be involved in drug interactions [13]. Therefore, usually, host proteases can be used as potential therapeutic targets. In many viruses, proteases play important roles in viral replication; therefore, proteases are commonly used as protein targets during the development of antiviral drug treatment [14].

Nelfinavir and lopinavir are protease inhibitors with high cytotoxic against HIV-infected cells. Lopinavir and ritonavir are protease inhibitors recommended for the treatment of SARS and MERS, which have similar mechanisms of action as HIV. The antiviral effects of nelfinavir on CoV have been studied in vitro, in Vero cells infected with SARS-CoV [15], [16]. It is important to pay attention to how infection develops in COVID-19 disease.

\section{Infection}

Scientists exploring how CoVs like COVID-19 infect human cells have shown that the SARS-CoV-2 spike (S) glycoprotein binds to the cell membrane protein angiotensin-converting enzyme 2 (ACE2) to enter human cells. COVID-19 has been shown to bind to ACE2 through the $S$ protein on its surface. During infection, the $S$ protein is cleaved into subunits, $S 1$ and S2. S1 contains the receptor binding domain (RBD) which allows CoVs to directly bind to the peptidase domain (PD) of ACE2. S2 then likely plays a role in membrane fusion. Chinese researchers have now used cryogenic electron microscopy to study the structure of the ACE2 when it is bound to one of its typical ligands, the amino acid transporter B0AT1, and also how the COVID-19 RBD may bind to the ACE2B0AT1 complex. These structures have previously not been identified and could aid in producing antivirals or a vaccine that can block $\mathrm{CoV}$ infection by targeting ACE2 (Figure 1) [3] 


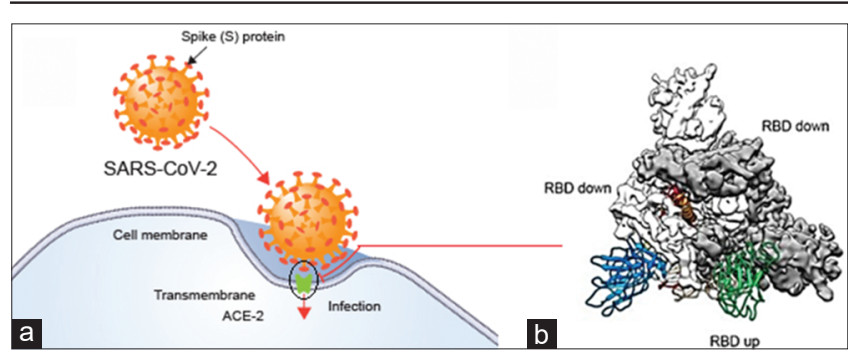

Figure 1: (a) Connection of the S1 receptor to the ACE2 receptor on the pulmonary cells. (b) Three-dimensional structure of the coupled receptor. S1 contains the receptor binding domain which allows coronaviruses to directly bind to the peptidase domain of ACE2

\section{The signs, symptoms, disease progression, and severity}

Symptoms of COVID-19 are non-specific and the disease presentation can range from no symptoms (asymptomatic) to severe pneumonia and death. As of February 20, 2020, and based on 55,924 laboratoryconfirmed cases, typical signs and symptoms include fever $(87.9 \%)$, dry cough $(67.7 \%)$, fatigue $(38.1 \%)$, sputum production $(33.4 \%)$, shortness of breath $(18.6 \%)$, sore throat $(13.9 \%)$, headache $(13.6 \%)$, myalgia or arthralgia (14.8\%), chills $(11.4 \%)$, nausea or vomiting $(5.0 \%)$, nasal congestion $(4.8 \%)$, diarrhea $(3.7 \%)$, and hemoptysis $(0.9 \%)$, and conjunctival congestion (0.8\%) (WHO, 2019).

People with COVID-19 generally develop signs and symptoms, including mild respiratory symptoms and fever, on an average of 5-6 days after infection (mean incubation period 5-6 days, range 1-14 days) (WHO, 2019).

Most people infected with COVID-19 virus have mild disease and recover. Approximately $80 \%$ of laboratory confirmed patients have had mildto-moderate disease, including non-pneumonia and pneumonia cases, $13.8 \%$ have severe disease. Asymptomatic infection has been reported, but the majority of the relatively rare cases who are asymptomatic on the date of identification/report went on to develop disease. The proportion of truly asymptomatic infections is unclear but appears to be relatively rare and does not appear to be a major driver of transmission. People at high risk for serious illness and death include people over 60 years and those with underlying conditions such as hypertension, diabetes, cardiovascular disease, chronic respiratory disease, and cancer. Disease in children appears to be relatively rare and mild, with approximately $2.4 \%$ of all reported cases among cases under 19 years old. A very small proportion of those under 19 had severe $(2.5 \%)$ or critical (0.2\%) disease [17], [18], [19].

Mortality increases with age, with the highest mortality among people over 80 years of age (case fatality rate [CFR] 21.9\%). The CFR is higher among males compared to females $(4.7 \%$ vs. $2.8 \%)$. By occupation, patients who reported being retirees had the highest CFR at $8.9 \%$. While patients who reported no comorbid conditions had a CFR of $1.4 \%$, patients with comorbid conditions had much higher rates: $13.2 \%$ for those with cardiovascular disease, $9.2 \%$ for diabetes, $8.4 \%$ for hypertension, $8.0 \%$ for chronic respiratory disease, and $7.6 \%$ for cancer [19].

\section{CoVs in children}

According to a new study, CoV disease 2019 (COVID-19) has shown mild symptoms among children in China. However, the young age group is not entirely aware of the virus. Infants had a higher disease rate than older children. It is suggested that further investigation is needed to understand the role of children in the spread of the virus in the community. Approximately $75 \%$ of suspected children had COVID-19. Regarding the gender, no significant difference was observed. Approximately $4 \%$ of children patients were asymptomatic, $51 \%$ had mild and $39 \%$ had moderate symptoms. Moreover, compared to $18.5 \%$ of adults, approximately $6 \%$ of children showed severe or critical condition (with a 14-year-old boy dead). The gap is perceived to be confusing to researchers, suggesting that it may be related to both exposure and host factors. Several reasons were proposed, including (a) children's low exposure to the virus; (b) high levels of antibodies against viruses; and (c) developing different immune responses. The virus may also not bind to children's cells. The present study also found that the illness in infants is more serious than in older children. Compared to $7 \%$ of children aged $1-5$ years, only $11 \%$ of infants had severe or critical condition [20]. A similar study suggested that children are more susceptible to upper respiratory tract involvement rather than lower respiratory tract involvement. There is also evidence of stool shedding for several weeks after diagnosis leading to concerns about oral-fecal transmission of the virus, especially in infants and toddlers who are not toilet trained, and for viral replication in the gastrointestinal tract [6].

Data on individuals aged 18 years old and under suggest that there is a relatively low attack rate in this age group (2.4\% of all reported cases). Within Wuhan, among testing of ILI samples, no children were positive in November and December of 2019 and in the first 2 weeks of January 2020. From available data, and in the absence of results from serologic studies, it is not possible to determine the extent of infection among children, what role children play in transmission, whether children are less susceptible or if they present differently clinically (i.e., generally milder presentations). The Joint Mission learned that infected children have largely been identified through contact tracing in households of adults. Of note, people interviewed by the Joint Mission Team could not recall episodes in which transmission occurred from a child to an adult [19]. 


\section{Clinical manifestations}

The virus was found in pediatric patients, from 1-month-old infants to 19 years old, and based on the evidences, most have been infected by family members [4]. General symptoms of the early patients included fever $98 \%$, cough $76 \%$, muscle aches or fatigue $44 \%$, shortness of breath (in 2 months old infants, with cough, difficulty breathing, and breathing faster than $60 / \mathrm{min}$; in 1-5 years old infants, with cough, difficulty breathing, and breathing faster than 40 breaths/min) $55 \%$, and acute respiratory distress syndrome (ARDS) $29 \%$. In another study, lymphopenia (a decrease in the number of lymphocytes in the blood) was seen in $80 \%$ of adult patients, while $<25 \%$ of children patients had mild lymphopenia, indicating the severity of infection in these patients. Chest computed tomography (CT) of children showed only one patient with bilateral groundglass opacity, as in adults [5]. In another report by Xia on 20 children, $70 \%$ of cases showed leukopenia, $10 \%$ leukocytosis, and 35\% lymphopenia. Eight cases were found to be infected with other respiratory pathogens such as mycoplasma and influenza. Lung scan also showed 10 abscesses on both sides of the lung. In 6 cases, only one side of the lung had abscess, and in 12 cases, there observed ground-glass opacities [21].

General symptoms include fever 99\%, dry cough $59 \%$, and muscle pain or fatigue $70 \%$. Furthermore, $26 \%$ of patients were transferred to ICU and $4 \%$ of them died. Interestingly, $41 \%$ of patients were infected in hospitals. Severe cases of ARDS and acute kidney failure have also been reported. Symptoms the patients may develop include increased C-reactive protein (CRP) protein, erythrocyte sedimentation rate, lactate dehydrogenase, creatinine, and prothrombin clotting time [17]. Another study by Wei et al. indicated that all children were infected by their family members, showing mild symptoms [22].

Inflammatory markers including CRP and procalcitonin showed a $13.6 \%$ and $10.6 \%$ increase, respectively [10]. After studying four infected children, two showed respiratory disorder and one severe decrease $(1 \mathrm{mg} / \mathrm{L})$ in CRP. It is while both proteins in the progressed stages significantly increased in adults [23]. Children CT showed opacity in different regions. The damage was largely similar to that of adults (Figure 2). An important issue was the change in CRP protein and lymphocytes, in which, while the latter had many changes, the former changed a little, indicating a significant difference compared to adults [23], [24].

\section{Important points}

There are several salient points from this article. First, although children are less likely than older adults to become severely ill, there are subpopulations of children with an increased risk for more significant illness. These data on disease severity are consistent with data on non-COVID-19 CoVs. The authors of one viral surveillance study in a PICU in China reported that CoV was detected in more children with ARDS than Human metapneumovirus [27]. The authors of another study conducted on hospitalized Norwegian children detected CoVs in $10 \%$ of hospitalized children with respiratory tract infections [6]. Younger age, underlying pulmonary pathology, and immune compromising conditions have been associated with more severe outcomes with nonCOVID-19 CoV infections in children [28].

Second, the attributable risk for severe disease from COVID-19 in children is challenging to discern. The previous studies have revealed that children from whom CoVs are detected from the respiratory tract can have viral coinfections in up to $75 \%$ of cases [27]. In the study by Dong et al. [4], testing for other viruses was not standardized, and two-thirds of cases were clinically diagnosed, not virologically confirmed. In addition, children without virological confirmation were more likely to have severe disease than children from whom COVID-19 was detected, potentially because their symptoms were caused by other pathogens [29].

Third, children may play an important role in community-based viral transmission.

Fourth, most children are at a high level of immune function. According to studies, while the lymphocytes had many changes, the CRP protein changed a little [24]. Studies showed that an increase in lymphocytes is associated with specific immunity. In people with stronger immune system, lymphocytes, especially $\mathrm{T}$ lymphocytes, act more rapidly and specifically eliminate the pathogen. On the other hand, in people with weaker immune system, COVID-19

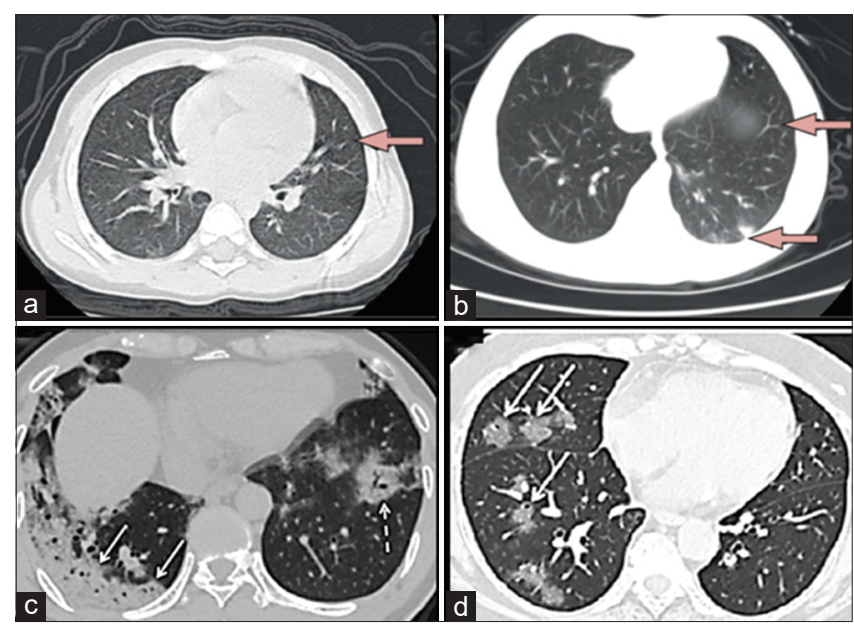

Figure 2: (a) Computed tomography (CT) of a 10-year-old boy showing multiple opacities in lower lobes of both lungs (arrow); (b) CT of a 1.5-year-old girl showing multiple ground-glass opacities with a big patchy opacity in the right lung (arrows); (c) an axial CT image obtained without intravenous contrast in a 42-year-old male in the "late" time group (10 days from symptom onset to this CT) shows bilateral consolidative opacities, with a striking peripheral distribution in the right lower lobe (solid arrows), and with a rounded morphology in the left lower lobe (dashed arrow); (d) an axial CT image obtained without intravenous contrast in a 56-year-old female shows groundglass opacities with a rounded morphology (arrows) in the right middle and lower lobes. The left lung was normal [25], [26] 
exacerbates inflammation by causing pneumonia and increased cytokines. Similarly, the SARS virus is associated with a sharp decrease in the number of T-cells in the blood [30], [31], [32], [33]. The bottom line is that most children produce less inflammatory protein because of their immune system, and instead lymphocytes do their job. However, in people with weaker immune system, especially adults and the elderly, inflammatory proteins are produced, increasing the inflammation and worsening of CoV.

\section{Specific safety in children and COVID-19}

The human immune system is a complex network of specialized cells, tissues, and organs that are responsible for identifying and eliminating pathogens. Intrinsic and specific immune systems are the two main parts of the immune system. Intrinsic immunity is a general defense system consisting of inhibitory factors such as mucosa and skin and a specific immune system composed of cells that, with advanced mechanisms, identify only certain pathogens. In viral infection, T lymphocytes play the most important role in specific immunity. In summary, these viruses are specifically identified and killed by lymphocytes in a very complex cellular response [34], [35], [36]. Normally, after detection of viral compounds by cellular receptors, an appropriate and effective antiviral response is initiated by the immune system, which includes the production of a variety of cytokines and immune and inflammatory responses. Interferons I (IFN_ $\beta$ and IFN- $\alpha$ molecules) are key cytokines produced after virus infection that induces the onset of an immune response and subsequent adaptation [37], [38]. The immune response to the $\mathrm{CoV}$ is that $\mathrm{CoV}$ infects macrophages and then the macrophages deliver CoV antigen to the $\mathrm{T}$ cell. This process leads to the activation and detection of $\mathrm{T}$ cells and the increase in the production of various cytokines, followed by the widespread release of cytokines to enhance the immune response. Continued production of these mediators has a negative effect on NK function and $\mathrm{T}$ cell activation [38].

In people with stronger immune systems, lymphocytes, especially $T$ cells, act more rapidly and specifically kill the pathogen. However, in people with a weaker immune system, COVID-19 causes acute inflammation by causing pneumonia and increasing cytokines and decreasing T cells [30], [39], [40].

This suggests a large role for lymphocytes in specific immunity in relation to their impact on the recovery of corona disease. The important results of the reviewed articles show that there are a large number of T cells in children, which have an impact on the quality of function of the specific immune system in children. In many children, milder symptoms have been observed than in adults due to the specific function of the immune system [24]. The reason for the strength of the immune system of children compared to adults can be summarized in several issues. First, children are exposed to a variety of pathogens for the $1^{\text {st }}$ time in the early years of life, and second, children have the ability to rapidly produce natural antibodies with broad reactivity that has not yet been selected and shaped by the reaction to common environmental pathogens that are more prepared to fight $\mathrm{T}$ cells in the body [41], [42], [43].

\section{Treatment}

A recent paper reports the inhibitory effect of Ramsdevir (a new antiviral drug) and chloroquine (an old antimicrobial drug) on the growth of SARS-CoV-2 in vitro and an initial clinical trial conducted on Chinese patients with COVID-19. It was also shown that chloroquine had a significant effect on the clinical outcome and clearance of the virus compared to the control groups [44].

Chinese experts recommend that patients with mild, moderate, and severe COVID-19 pneumonia without chloroquine contraindication be treated with 500 $\mathrm{mg}$ of chloroquine twice daily 10 days. On the other hand, 18,264 (24\%) reported cases have improved as of February 20. An encouraging report on February 20 from the Guangdong CDC indicated that out of 125 severe cases, $33(26.4 \%)$ were recovered and discharged and 58 $(46.4 \%)$ recovered and classified as mild/moderate cases (i.e., + mild pneumonia). Of course, there have also been severe cases, with $13.4 \%$ of deaths so far. Early detection and contact with physician may improve treatment [19].

Other adjunctive treatments in China with the help of Chinese medicine have been performed on COVID-19 patients, including use of antioxidants. The current studies in China show that antioxidants are effective in boosting the immune system and reducing inflammation in patients with COVID-19 [45], [46], [47]. Another treatment currently under trial is the production of the vaccine; however, because of the consecutive mutations in the viral antigens, the investigations mostly focused on inhibiting the protease enzymes of the virus [15], [48]. Plasma therapy is another solution that the US Food and Drug Administration and WHO are looking for. It uses blood antibodies from the recovered patients, which is still in the experimental phase [49], [50].

Studies on children recommended the use of therapeutic drugs in reasonable and lowest doses at different ages, and like adults, antioxidants are the priority. In a study conducted in Wuhan, China, the use of antioxidants was recommended as adjunctive therapy for the entire high-sensitivity groups [45], [47], [47], [51].

\section{Conclusion}

Children are also diagnosed with COVID-19 like adults. Despite the low prevalence of the disease in 
children, the issue of prevention and immunosuppression in children is very important. The findings showed that children responded better to $\mathrm{CoV}$ than adults because of specific immune function in children.

Many studies have been published focusing on epidemiology, etiology, clinical manifestations, and diagnosis, prevention, and control. However, studies examining prevention and control measures have gradually increased. Government agencies have rapidly incorporated recent scientific findings into public policy at the community, regional, and national levels to slow or prevent further expansion of COVID-19. Our suggestion is to evaluate the difference in children's immune system function in the face of CoV compared to the adults and to provide treatment options for children and those with weaker immune systems. It is also proposed that the scientific community conducts further studies to provide valid and effective ways to manage this type of public health hazard both short and long term.

\section{References}

1. Huang $\mathrm{C}$, Wang $\mathrm{Y}, \mathrm{Li} X$, Ren L, Zhao J, Hu Y, et al. Clinical features of patients infected with 2019 novel coronavirus in Wuhan, China. Lancet. 2020;395(10223):497-506.

2. Lu R, Zhao X, Li J, Niu P, Yang B, Wu H, et al. Genomic characterisation and epidemiology of 2019 novel coronavirus: Implications for virus origins and receptor binding. Lancet. 2020;395(10224):565-74.

PMid:32007145

3. Cahyono B, Ariani J, Failasufa H, Suzery M. Extraction of homologous compounds of curcuminoid isolated from temulawak (Curcuma xanthorriza roxb.) plant. Rasayan J Chem. 2019;12(1):7-13. https://doi.org/10.31788/rjc.2019.1213092

4. Pediatric Branch of Hubei Medical Association; Pediatric Branch of Wuhan Medical Association; Pediatric Medical Quality Control Center of Hubei. Recommendation for the diagnosis and treatment of novel coronavirus infection in children in Hubei province (trial version 1). Zhongguo Dang Dai Er Ke Za Zhi. 2020;22(2):96-9. https://doi.org/10.46234/ccdcw2020.022 PMid:32051073

5. Liu W, Zhang Q, Chen J, Xiang R, Song H, Shu S, et al. Detection of covid-19 in children in early January 2020 in Wuhan, China. N Engl J Med. 2020;382(14):1370-1.

PMid:32163697

6. Cai J, Xu J, Lin D, Yang Z, Xu L, Qu Z, et al. A case series of children with 2019 novel coronavirus infection: Clinical and epidemiological features. Clin Infect Dis. 2020;2020:ciaa198. PMid:32112072

7. Medical Expert Group of Tongji Hospital. Quick Guide to the Diagnosis and Treatment of Pneumonia for Novel Coronavirus Infections. $3^{\text {rd }}$ ed. New Zealand: Herald of Medicine; 2020. Available from: http://www.kns.cnki.net/kcms/detail/42.129 3.r.20200130.1803.002.html. [Last accessed on 2020 Feb 02].

8. Mission T. Report of the WHO-China Joint Mission on Coronavirus Disease 2019 (COVID-19). Geneva: World Health Organization; 2020.

9. Rothe C, Schunk M, Sothmann P, Bretzel G, Froeschl G, Wallrauch C, et al. Transmission of 2019-nCoV infection from an asymptomatic contact in Germany. N Engl J Med. 2020;382(10):970-71.

PMid:32003551

10. Drexler JF, Gloza-Rausch F, Glende J, Corman VM, Muth D, Goettsche $\mathrm{M}$, et al. Genomic characterization of severe acute respiratory syndrome-related coronavirus in European bats and classification of coronaviruses based on partial RNA-dependent RNA polymerase gene sequences. J Virol. 2010;84(21):11336-49. https://doi.org/10.1128/jvi.00650-10 PMid:20686038

11. Zhavoronkov A, Aladinskiy V, Zhebrak A, Zagribelnyy B, Terentiev V, Bezrukov DS, et al. Potential COVID-2019 3C-like Protease Inhibitors Designed Using Generative Deep Learning Approaches. Hong Kong: Insilico Medicine Ltd.; 2020. p. 307.

12. Liu $X$, Zhang B, Jin Z, Yang $H$, Rao Z. The Crytal Structure of 2019-NCoV Main Protease in Complex with an Inhibitor N3. United States: RCSB Protein Data Bank; 2020.

13. Liu X, Wang XJ. Potential inhibitors against 2019-nCoV coronavirus $\mathrm{M}$ protease from clinically approved medicines. $\mathrm{J}$ Genet Genomics. 2020;47(2):119-21. https://doi.org/10.1016/j. jgg.2020.02.001

PMid:32173287

14. Chang KO, Kim Y, Lovell S, Rathnayake AD, Groutas WC Antiviral drug discovery: Norovirus proteases and development of inhibitors. Viruses. 2019;11(2):197. https://doi.org/10.3390/ v11020197 PMid:30823509

15. Yamamoto N, Yang R, Yoshinaka Y, Amari S, Nakano T, Cinatld J, et al. HIV protease inhibitor nelfinavir inhibits replication of SARS-associated coronavirus. Biochem Biophys Res Commun. 2004;318(3):719-25. https://doi.org/10.1016/j.bbrc.2004.04.083

16. Li JY, You Z, Wang Q, Zhou ZJ, Qiu Y, Luo R, et al. The epidemic of 2019-novel-coronavirus (2019-nCoV) pneumonia and insights for emerging infectious diseases in the future. Microbes Infect. 2020;22(2):80-5. https://doi.org/10.1016/j.micinf.2020.02.002 PMid:32087334

17. Wang D, Hu B, Hu C, Zhu F, Liu X, Zhang J, et al. Clinical characteristics of 138 hospitalized patients with 2019 novel coronavirus-infected pneumonia in Wuhan, China. JAMA. 2020;323(11):1061-9.

PMid:32031570

18. Wang C, Wang $X$. Prevalence, nosocomial infection and psychological prevention of novel coronavirus infection. Chin General Pract Nurs. 2020;18:2-3.

19. World Health Organization. Coronavirus Disease (COVID2019) Situation Reports; 2020. Available from: https://www. who.int/emergencies/diseases/novel-coronavirus2019/ situation-reports.

20. Cruz A, Zeichner S. COVID-19 in children: Initial characterization of the pediatric disease. Pediatrics. 2020;145(6):e20200834. https://doi.org/10.1542/peds.2020-0834 PMid:32179659

21. Xia W, Shao J, Guo Y, Peng X, Li Z, Hu D. Clinical and CT features in pediatric patients with COVID-19 infection: Different points from adults. Pediatr Pulmonol. 2020;55(5):1169-74. PMid:32134205

22. Wei M, Yuan J, Liu Y, Fu T, Yu X, Zhang ZJ. Novel coronavirus infection in hospitalized infants under 1 year of age in China. JAMA. 2020;323(13):1313-4. PMid:32058570

23. Lippi G, Plebani M. Laboratory abnormalities in patients with COVID-2019 infection. Clin Chem Lab Med. 2020;58(7):1131-4. https://doi.org/10.1515/cclm-2020-0198

PMid:32119647

24. Wang X, Yuan J, Zheng YJ, Chen J, Bao YM, Wang YR, et al. 
Retracted: Clinical and epidemiological characteristics of 34 children with 2019 novel coronavirus infection in Shenzhen. Zhonghua Er Ke Za Zhi. 2020;58:E008.

\section{PMid:32062875}

25. Bernheim A, Mei X, Huang $M$, Yang $Y$, Fayad ZA, Zhang $N$, et al. Chest CT findings in coronavirus disease-19 (COVID-19): Relationship to duration of infection. Radiology. 2020;295(3):200463. https://doi.org/10.1148/radiol.2020200463

26. Qiu H, Wu J, Hong L, Luo Y, Song Q, Chen D. Clinical and epidemiological features of 36 children with coronavirus disease 2019 (COVID-19) in Zhejiang, China: An observational cohort study. Lancet Infect Dis. 2020;20(6):P689-96. https://doi. org/10.1016/s1473-3099(20)30198-5

27. Li YT, Liang $Y$, Ling YS, Duan MQ, Pan L, Chen ZG. The spectrum of viral pathogens in children with severe acute lower respiratory tract infection: A 3-year prospective study in the pediatric intensive care unit. J Med Virol. 2019;91(9):1633-42. https://doi.org/10.1002/jmv.25502

PMid:31081548

28. Heimdal I, Moe N, Krokstad S, Christensen A, Skanke LH, Nordbø SA, et al. Human coronavirus in hospitalized children with respiratory tract infections: A 9-year population-based study from Norway. J Infect Dis. 2019;219(8):1198-206. https:// doi.org/10.1093/infdis/jiy646

PMid:30418633

29. Dong Y, Mo X, Hu Y, Qi X, Jiang F, Jiang Z, et al. Epidemiology of COVID-19 among children in China. Pediatrics. 2020;145(6):e20200702.

PMid:32179660

30. Park YJ, Walls AC, Wang Z, Sauer MM, Li W, Tortorici MA, et al. Structures of MERS-CoV spike glycoprotein in complex with sialoside attachment receptors. Nat Struct Mol Biol. 2019;26(12):1151-7. https://doi.org/10.1038/ s41594-019-0334-7

PMid:31792450

31. Wan Y, Shang J, Graham R, Baric RS, Li F. Receptor recognition by the novel coronavirus from Wuhan: An analysis based on decade-long structural studies of SARS coronavirus. J Virol. 2020;94(7):20.

32. Diao B, Wang C, Tan Y, Chen X, Liu Y, Ning L, et al. Reduction and functional exhaustion of $T$ cells in patients with coronavirus disease 2019 (COVID-19). Front Immunol. 2020;11:827. https:// doi.org/10.3389/fimmu.2020.00827

PMid:32425950

33. Channappanavar R, Zhao J, Perlman S. T cell-mediated immune response to respiratory coronaviruses. Immunol Res. 2014;59(1-3):118-28. https://doi.org/10.1007/s12026-014-8534-z PMid:24845462

34. McComb S, Thiriot A, Krishnan L, Stark F. Introduction to the immune system. In: Methods and Protocols, Methods in Molecular Biology. Ch. 1. Berlin, Germany: Springer; 2013. p. 1061. https://doi.org/10.1007/978-1-62703-589-7_1

35. Yewdell JW, Bennink JR. Mechanisms of Viral Interference with MHC Class I Antigen Processing and Presentation. Annu Rev Cell Dev Biol. 1999;15:579-606.

PMid:10611973

36. Tordesillas L, Lozano-Ojalvo D, Dunkin D, Mondoulet L, Agudo J, Merad M, et al. PDL2(+) CD11b(+) dermal dendritic cells capture topical antigen through hair follicles to prime $\mathrm{LAP}(+)$ tregs. Nat Commun. 2018;9(1):5238. https://doi. org/10.1038/s41467-018-07716-7

PMid:30531969

37. Kawai T, Shizuo A. Innate immune recognition of viral infection. Nat Immunol. 2006;7(2):131-7.

PMid: 16424890
38. Li G, Fan Y, Lai Y, Zonghui L, Peiwen Z, Pan P, et al. Coronavirus infections and immune responses. J Med Virol. 2020;92(4):424-32. PMid:31981224

39. Yazdanpanah F, Hamblin MR, Rezaei N. The immune system and COVID-19: Friend or foe? Life Sci. 2020 Sep 1; 256: 117900. PMid:2502542

40. Tufan A, Avanoğlu Güler A, Matucci-Cerinic M. COVID-19, immune system response, hyperinflammation and repurposing antirheumatic drugs. Turk J Med Sci. 2020; 50(3): 620-632.

41. Capolunghi F, Rosado MM, Sinibaldi M, Aranburu A, Carsetti R. Why do we need IgM memory B cells? Immunol Lett. 2013;152(2):114-20. https://doi.org/10.1016/j.imlet.2013.04.007 PMid:23660557

42. Throsby $M$, van den Brink E, Jongeneelen M, Poon LL, Alard P, Cornelissen $\mathrm{L}$, et al. Heterosubtypic neutralizing monoclonal antibodies cross-protective against $\mathrm{H} 5 \mathrm{~N} 1$ and $\mathrm{H} 1 \mathrm{~N} 1$ recovered from human IgM ${ }^{+}$memory B cells. PLoS One. 2008;3(12):3e3942. https://doi.org/10.1371/journal.pone.0003942 PMid: 19079604

43. Grimsholm O, Mortari EP, Davydov AN, Shugay M, Obraztsova AS, Bocci C, et al. The interplay between CD27dull and CD27bright $B$ cells ensures the flexibility, stability, and resilience of human B cell memory. Cell Rep. 2020;30(9):2963-77. https://doi.org/10.1016/j.celrep.2020.02.022 PMid:32130900

44. Gao J, Tian Z, Yang X. Breakthrough: Chloroquine phosphate has shown apparent efficacy in treatment of COVID-19 associated pneumonia in clinical studies. Biosci Trends. 2020;14(1):72-3. https://doi.org/10.5582/bst.2020.01047 PMid:32074550

45. Peterhans E. Oxidants and antioxidants in viral diseases: Disease mechanisms and metabolic regulation. J Nutr. 1997;127(5):962S-5. https://doi.org/10.1093/jn/127.5.962s PMid:9164274

46. Tenero L, Piazza M, Zanoni L, Bodini A, Peroni D, Piacentini GL. Antioxidant supplementation and exhaled nitric oxide in children with asthma. Allergy Asthma Proc. 2016;37(1):e8-13. https://doi. org/10.2500/aap.2016.37.3920 PMid:26831840

47. Jin YH, Cai L, Cheng ZS, Cheng H, Deng T, Fan YP, et al. A rapid advice guideline for the diagnosis and treatment of 2019 novel coronavirus (2019-nCoV) infected pneumonia (standard version). Military Med Res. 2020;7(1):4

48. Ghosh AK, Osswald HL, Prato G. Recent progress in the development of HIV-1 protease inhibitors for the treatment of HIV/AIDS. J Med Chem. 2016;59(11):5172-208. https://doi. org/10.1021/acs.jmedchem.5b01697 PMid:26799988

49. Bolles $M$, Deming $D$, Long $K$, Agnihothram S, Whitmore A Ferris $M$, et al. A double-inactivated severe acute respiratory syndrome coronavirus vaccine provides incomplete protection in mice and induces increased eosinophilic proinflammatory pulmonary response upon challenge. J Virol. 2011;85(23):12201-15. https://doi.org/10.1128/jvi.06048-11 PMid:21937658

50. Wu Z, McGoogan JM. Characteristics of and important lessons from the coronavirus disease 2019 (COVID-19) outbreak in China: Summary of a report of 72314 cases from the Chinese center for disease control and prevention. JAMA. 2020;323(13):1239-42. https://doi.org/10.1001/jama.2020.2648

51. Gh NM, Oskouie AA, Aliannejad R, Rezaei-Tavirani M, Tavallaie S, Baghban AA, et al. Pro-oxidant-antioxidant balance in Iranian veterans with sulfur mustard toxicity and different levels of pulmonary disorders. Drug Chem Toxicol. 2016;39(4):362-6. https://doi.org/10.3109/01480545.2015.1122033 